may be needed as well as treatment with antiepileptic drugs in most cases. Loud snoring, snuffling, or choking during sleep, especially combined with nocturnal enuresis and very restless sleep, suggest obstructive sleep apnoea, for which adenotonsillectomy may be beneficial. ${ }^{10}$ Additional effective measures, depending on the problem, include making the environment safe to avoid accidental injury during sleep walking and preventing night time fears and nightmares caused by disturbing stories or television programmes before the child goes to bed.

Signs to suggest that a sleep disorder is more than developmental and that further investigation is required include very frequent occurrence, onset in or persistence into late childhood, appearance after a traumatic event, and other evidence of psychological disturbance. In these circumstances psychological help may well be needed. In the case of undiagnosed parasomnia video recordings to identify the precise nature of the attacks can be valuable, preferably accompanied by electroencephalographic monitoring.

The help available for children with sleep disorders and their parents could be improved if doctors were taught more about sleep problems and if protocols for taking the history paid more attention to sleep. Guidelines for teaching medical students about sleep disorders have been published in the United States, ${ }^{11}$ but there has been no comparable development in Britain. Many important research issues need to be explored. For example, how can the quality of children's sleep be judged? What are the effects of poor quality sleep on daytime learning and behaviour? What types of sleep disturbance mean that the child is psychologically disturbed? How do the severe sleep disorders in children with a mental handicap come about, and how can they be treated? What sleep problems complicate serious illness and how might their effects be minimised? Answers to such questions would be valuable to general practitioners, paediatricians, and to others concerned with the health and welfare of children.

GREGORY STORES

Clinical Reader,

University of Oxford,

Section of Child and Adolescent Psychiatry,

Park Hospital for Children,

Oxford OX3 7LQ

1 Association of Sleep Disorders Centers. Diagnostic classification of sleep and arousal disorders. Sleep 1979;2:1-137.

Clements J, Wing L, Dunn G. Sleep problems in handicapped children: a preliminary study. $\mathcal{f}$ Child Psychol Psychiatry 1986;27:399-407.

3 Stores G. Confusions concerning sleep disorders and the epilepsies in children and adolescents. $\mathrm{Br}$ f Psychiatry (in press).

Wooten V. Medical causes of insomnia. In: Kryger MH, Roth T, Dement W'C, eds. Principles and practice of sleep medicine. Philadelphia: Saunders, 1989:456-75.

practice of sleep medicme. Philadelphia: Saunders, 1989:456-75.
Simonds JF, Parraga H. Sleep behaviors and disorders in children and adolescents evaluated in Simonds JF, Parraga H. Sleep behaviors and disorders in children and
psychiatric clinics. Developmental and Behavioral Pediatrics 1984;5:6-10.

Douglas J, Richman N. My child won't sleep. Harmondsworth: Penguin, 1984

7 Simonoff E, Stores G. Controlled trial of trimeprazine tartrate for night waking. Arch IDis Child $1987 ; 62: 253-7$

8 Ferber R. Solve your child's sleep problems. London: Dorling Kindersley, 1989.

9 Lask B. Novel and non-toxic treatment for night terrors. Br Med f 1988;297:592.

10 Stradling JR, Thomas G, Warley ARH, Williams P, Freeland A. Effect of adenotonsillectomy on noctural hypoxaemia, sleep disturbance, and symptoms in snoring children. Lancet 1990;335: $249-53$.

11 Medical School Curriculum Task Force. The Medical School Curriculum Consensus Workshop: consensus document. Sleep 1988;11:566-70.

\title{
Medical termination of pregnancy
}

\section{Combined with prostaglandin $R U 486$ is effective}

The uterine progesterone receptor was discovered in $1970,{ }^{12}$ and before long it was recognised as a suitable molecular target for an antigestagen. In 1982 Philibert and colleagues at Roussel-Uclaf reported the synthesis of RU 38486, "an antiglucocorticoid with a new mechanism of antihormone activity." The first two numerals were soon dropped, and the term RU 486 is now more often used than the approved name, mifepristone (17 $\beta$-hydroxy-11 $\beta$ (dimethylaminophenyl)$17 \alpha$-(1-propynyl)estra-4,9-dien-3-one). It has been termed a "designer drug," the first in a new class of compounds that compete with progesterone for its specific receptors and so antagonise its action. It is a derivative of norethisterone, the main change to the molecule being the dimethylaminophenol group at the specific position and spatial orientation $(11 \beta)$ that has proved to be of great importance for antihormonal function.' It binds with high affinity to the progesterone receptor in target organs, including the endometrium. Depending on the model studied it has virtually no agonist activity and also almost no effect on oestrogen receptors in the uterus or mineralocorticoid receptors in the kidney. ${ }^{+}$As the glucocorticoid and progesterone receptors have a very similar structure ${ }^{1}$ RU 486 also has antiglucocorticoid activity, but this is negligible in short term use at the prescribed dose.

The pre-embryo reaches the uterus within a few days and implants in the endometrium about seven to eight days after fertilisation. ${ }^{6}$ When the pregnancy proceeds (and most often it does not) human chorionic gonadotrophin almost immediately is detectable, and this prevents regression of the corpus luteum. Continued secretion of progesterone from the ovary - and its reception at the endometrium - are essential for the maintenance of early pregnancy. By the seventh week of pregnancy, however, enucleation of the corpus luteum no longer leads to failure of the pregnancy. ${ }^{7}$ Thereafter sufficient progesterone is produced by the placenta, and this probably explains the diminishing effectiveness of mifepristone with or without prostaglandins in terminating pregnancies beyond the 49th day.

The pharmacokinetics and metabolism of mifepristone have been studied in detail. ${ }^{18}$ Its bioavailability after oral absorption is of the order of $70 \%$. The peak concentration in the plasma is achieved in one to two hours; and though the half life is 12 to 24 hours, the drug's complex metabolism ensures a high plasma concentration for several days after a single oral dose greater than $25 \mathrm{mg}$. Mifepristone is distributed more slowly after parenteral administration and is also more active. The vaginal route is ineffective. ${ }^{1}$

The effects of mifepristone vary with the phase of the menstrual cycle. ${ }^{+5}$ Given during the first three days of the follicular phase there is no change in the events of the normal cycle apart from a small inhibition of early production of oestradiol. ${ }^{9}$ But when given throughout follicular development in small doses such as $25 \mathrm{mg}$ a day ${ }^{10}$ or even as low as 10 mg a day ${ }^{11}$ the drug inhibits ovulation and lengthens the cycle by about seven days. This observation, confirming the role of progesterone in the processes of follicle maturation, the luteinising hormone surge, and ovulation, suggests a basis for an oestrogen free systemic contraceptive. ${ }^{151213}$

If given shortly after ovulation the drug will inhibit the formation of the corpus luteum. But given in the mid-luteal phase there seems to be little or no luteolytic effect. ${ }^{1+15}$ There 
is a direct effect due to blocking of progesterone activity in the endometrium, with bleeding during the administration of RU 486 followed by a second episode at the end of the lifespan of the corpus luteum several days later. ${ }^{14}$ There is a dose dependent decrease in secretion of luteinising hormone, but it is followed by a rebound increase in the concentration of luteinising hormone and of the hormones from the corpus luteum.

If mifepristone is given at the end of the luteal phase there is luteolysis with consistent precipitation of the menses ${ }^{514}$; but in the presence of an implanted embryo "human chorionic gonadotrophin rescue" seems to occur. Two women out of 12 with positive results on sensitive pregnancy tests at the time of the expected menses conceived despite treatment for four days in the late luteal phase. ${ }^{16}$ When mifepristone was given as a single dose at the end of the cycle as a "menses inducer," nine of 48 patients with biochemical evidence of implantation continued with their pregnancy. ${ }^{17}$ In another, similar, study only one of 18 women showed this chorionic gonadotrophin rescue. ${ }^{18}$ Taken together these data suggest that the failure rate is too high for mifepristone to be used as a menses inducer. Other likely problems are the unpredictability of women's cycle lengths and the possible disruption of cycles after treatment. ${ }^{18}$

It remains possible that if the antigestagen were given earlier, within 72 hours of ovulation, it would interfere with the development of secretory endometrium sufficiently to prevent implantation. Studies of this option are in progress. Compared with the leading postcoital hormonal method described by Yuzpe and Lancee ${ }^{19}$ it is likely that there would be a lower frequency of side effects. ${ }^{20}$ But the biggest uncertainty with this application of the drug relates to efficacy. Baulieu has suggested a related possibility, luteal phase contraception, in which a very low dose daily might be taken for the last 10-12 days of the cycle (or starting at the woman's presentation after mid-cycle coitus) until normal menstruation occurs.

\section{Induction of early abortion}

So is mifepristone clinically effective in the termination of early pregnancy? Given alone the failure rates are unacceptably high, with an incidence of complete abortion ranging from $85 \%$ in the first 35 days to less than $40 \%$ by 63 days of amenorrhoea. "As the drug increases the sensitivity of the uterus to prostaglandins, however, a combination of the two has been shown to be highly effective. ${ }^{2122}$ Currently most centres use a single dose of $600 \mathrm{mg}$ of mifepristone followed 36 to 48 hours later by either $0.25 \mathrm{mg}$ of sulprostone by injection or a single vaginal pessary of $1 \mathrm{mg}$ of gemeprost. In Edinburgh 187 of 188 women given this combination aborted completely; only one required curettage for retained products. ${ }^{11}$ There are very few side effects. A few women require analgesia during the passage of the fetus. Blood loss averages $70-80 \mathrm{ml}$, but occasionally a patient will require admission for emergency treatment. ${ }^{23}$ The transfusion rate was $0 \cdot 1 \%$ of the first 10251 women treated under the French National Demographic Institute's surveillance since October 1988 (B Aubeny, first congress of the European Society of Contraception, Paris, 1990).

There have now been extensive trials (chiefly under the auspices of the World Health Organisation) to investigate the optimal or minimum dose of antigestagen and prostaglandin and the route and timing. ${ }^{12425}$ A comparative trial showed that $0.5 \mathrm{mg}$ of gemeprost was as effective as $1 \mathrm{mg}$, but this dose may be obtained at present only by dividing the pessary in half. If sulprostone $0.125 \mathrm{mg}$ is injected the duration of bleeding is reduced at the price of some reduction in effectiveness (Aubeny, 1990). A study just published showed that an oral prostaglandin analogue $(10 \mathrm{mg}$ of 9 -methylene prostaglandin $\mathrm{E}_{2}$ ) given on days 3 and 4 after mifepristone $600 \mathrm{mg}$ was $95 \%$ successful in inducing complete abortion. ${ }^{26}$ Research is also in progress to develop a 48 hour delayed release prostaglandin system to be given at the same time as the antigestagen. ${ }^{27}$ Avoiding the second visit for treatment would be of particular value in countries such as Britain where treatment for abortion must be administered only in a licensed clinic or NHS hospital.

Already in France the mifepristone and prostaglandin combination is used by over 1000 women a week, and about 45000 treatments had been registered by May 1990 (Aubeny, 1990). It must be given in registered clinics under medical control, and there is a tightly regulated protocol: it can be given only to French nationals or people with a minimum of three months' residence in France; a week's delay is necessary for reflection; there must be adequate social support; specified contraindications must be observed; official forms must be signed and countersigned; mifepristone $600 \mathrm{mg}$ should be given no later than the 49th day of amenorrhoea and prostaglandin given 48 hours later with surveillance in the clinic for three to four hours; and there must be a follow up visit after five to nine days. ${ }^{28}$ Women must sign an agreement to accept surgical abortion in the event of failure - for fear of teratogenesis, though this has not been established in humans. Uterine bleeding lasts eight to 15 days, and in over $90 \%$ of cases no other treatment is needed. In the remainder a surgical curettage or suction procedure is still needed, either for heavy bleeding or because the combination treatment has failed to induce abortion (Aubeny, 1990).

\section{Second trimester abortion and other uses}

Pretreatment with the antigestagen is effective in softening the cervix before vacuum extraction. ${ }^{29}{ }^{30}$ It requires at least 24 hours to act, which compares unfavourably with three hours for a prostaglandin pessary, ${ }^{31}$ but the prostaglandin pessary is prone to lead to premature medical abortion. Pretreatment with mifepristone also reduces the force required to dilate the cervix in women who are not pregnant ${ }^{30}$ : this could be a useful application for planned outpatient procedures such as insertion or removal of an intrauterine device and hysteroscopy.

Mifepristone is also being evaluated in second trimester abortion. In a recent study women were randomly allocated to receive either $600 \mathrm{mg}$ of mifepristone or placebo tablets 36 hours before the first $1 \mathrm{mg}$ pessary of gemeprost. The number of pessaries required and the median number of hours between the first dose of prostaglandin and abortion were less among the pretreated women, who also suffered appreciably less pain-but there was no difference in the incidence of side effects. ${ }^{32}$

Mifepristone is effective in inducing labour in the presence of intrauterine fetal death, ${ }^{33}$ and it enhances the ability of oxytocin to induce labour in the rhesus monkey. ${ }^{34}$ These data plus those on cervical ripening suggest the possibility of using antigestagens to speed the onset of labour, provided that no hazard to the fetus in the third trimester is discovered. A recent small study showed a rise in fetal aldosterone concentration but no change in cortisol concentration four hours after administration of $600 \mathrm{mg}$ of mifepristone. ${ }^{35}$

The treatment with drugs of extrauterine pregnancy under carefully controlled conditions is an intriguing but so far unsuccessful research initiative. ${ }^{136}$ Mifepristone has been used experimentally in patients with Cushing's syndrome. It has no short term effect but may have a long term therapeutic use. ${ }^{37}$ As some breast, ovarian, and endometrial tumours have progesterone receptors the drug has been tested as a thera- 
peutic agent in a limited trial in advanced breast cancer. A transient improvement was noted in six of 27 women. ${ }^{38}$ Mifepristone may also have a place in treating endometriosis ${ }^{1}$ and certain types of meningioma. ${ }^{39}$

\section{Social, legal, and ethical issues}

Despite its potential wide usefulness many antiabortion bodies have united to oppose RU 486. They make the point that a black market for the drug could develop, with associated medical hazards. But such problems are more, not less, likely if the drug is driven underground. As Baird pointed out: "The valid point for discussion is whether it is ethical to carry out therapeutic abortion under any circumstances. While it is legal to carry out therapeutic abortion, surely it is incumbent on medical scientists to develop safe and effective means which will preserve the health of women?"11

In October 1988- on the day after the French marketing licence was given - the manufacturer suspended all sales. Although the largest holder of Roussel-Uclaf stock is the French government, over $36 \%$ is held by Hoechst of West Germany. Hoechst had earlier been accused of (but denied) manufacturing the poison gas used in Nazi concentration camps. Its management may have been afraid that opponents to abortion would revive this calumny; it brought heavy pressure on Dr Sakiz, the president of Roussel-Uclaf, to suspend sales. (It is a bizarre paradox of twentieth century history that Adolf Hitler explicitly condemned abortion as immoral. ${ }^{4}$ ) Two days later the French government ordered the company to resume distribution of the drug. Health minister Claude Evin said that executives of the company had been subjected to "scandalous pressure," which included anonymous threats to their wives and children. The drug, ordered Evin, should be made available "in the interest of

1 Baulieu E-E. RU-486 as an antiprogesterone steroid: from receptor to contragestion and beyond. JAMA 1989;262:1804-14.

2 Milgrom E, Atger $M$, Baulieu E-E. Progesterone in uterus and plasma, IV: progesterone receptor in guinea pig uterus cytosol. Steroids 1970;16:741-54

3 Philibert D, Deraedt R, Rournemine C, et al. RU 38486-an antiglucocorticoid with a new mechanism of antihormone activity. I Steroid Biochem 1982;17:68.

4 Potts M. RU 486: termination of a pregnancy in the privacy of one's home. NC Med $\mathcal{F}$ 1989;50: $531-6$

5 Herrmann W. The clinical use of RU 486 (mifepristone). Research in Reproduction 1989;21:3.

6 Baird DT. The use of antigestagens in fertility regulation. British fournal of Family Planning 1988;13(suppl):11-3.

7 Csapo AL Pulkkinen MO. Indispensability of the human corpus luteum in the maintenance of early pregnancy. Obstet Gynecol Surv 1978;33:69-81.

8 Deraedt R, Bonnat C, Busigny M, et al. Pharmacokinetics of RU 486. In: Baulieu E-E, Segal SJ, eds. The antiprogestin steroid RU 486 and human fertility control. New York: Plenum Press 1985: $103-22$.

9 Stuenkel CA, Garzo VG, Morris S, et al. Effects of the antiprogesterone RU 486 in the early follicular phase of the menstrual cycle. Fertil Steril 1990;53:642-6.

10 Luukkainen T, Heikinheimo O, Haukkamaa $M$, et al. Inhibition of folliculogenesis and ovulation by the antiprogesterone RU 486. Fertil Steril 1988;49:961-3.

1 Baird DT. An update on the use of antigestagens in fertility control. British fournal of Family Planning 1990;15(suppl):44-7.

$12 \mathrm{Liu} \mathrm{JH}$, Yen SS. Induction of midcycle gonadotropin surge by ovarian steroids in women: a critical evaluation. F Clin Endocrinol Metab 1983;57:797-802.

13 Kekkonen R, Alfthan H, Haukkamaa $M$, et al. Interference with ovulation by sequential treatment with the antiprogesterone RU 486 and synthetic progestin. Fertil Steril 1990;53:747-50.

14 Garzo VG, Liu J, Ulmann A, Baulieu E-E, Yen SS. Effects of an antiprogesterone (RU 486) on the hypothalamic-hypophyseal-ovarian-endometrial axis during the luteal phase of the menstrual cycle. $\mathcal{F}$ Clin Endocrinol Metab 1988;66:508-17.

15 Schaison G, George M, Lestrat N, Reinberg A, Baulieu E-E. Effects of the antiprogesterone steroid RU 486 during mid-luteal phase in normal women. I Clin Endocrinol Metab 1985;61:484-9.

6 Van Santen MR, Haspels AA. Interception III: postcoital luteal contraception by an antiprogestin mifepristone (RU 486) in 62 women. Contraception 1987;35:423-31.

17 Dubois C, Ulmann A, Baulieu E-E. Contragestion with late luteal administration of RU 486 (mifepristone). Fertil Steril 1988;50:593-6.

18 Lahteenmaki P, Alfthan H, Rapeli T, et al. Late postcoital treatment against pregnancy with antiprogesterone RU 486. Fertil Steril 1988;50:36-8.

19 Yuzpe AA, Lancee WJ. Ethinylestradiol and dl-norgestrel as a postcoital contraceptive. Fertil Steri 1977;28:932-6.

20 Rowlands S, Guillebaud J, Bounds W, Booth M. Side effects of anazol compared with an ethinyloestradiol/norgestrel combination when used for postcoital contraception. Contraception 1983;27:39-49.

21 Bygdeman M, Swahn M-L. Progesterone receptor blockage. Effect on uterine contractility and early pregnancy. Contraception 1985;32:45-51.

22 Cameron IT, Michie AF, Baird DT. Therapeutic abortion in early pregnancy with antiprogesterone RU 486 alone or in combination with prostaglandin analogue (gemeprost). Contraception 1986;34:459-67.

23 Rodger MW, Baird DT. Blood loss following induction of early abortion using mifepristone (RU 486) and a prostaglandin analogue (gemeprost). Contraception 1989;40:439-47.

24 Rodger MW, Baird DT. Induction of therapeutic abortion in early pregnancy with mifepristone in combination with prostaglandin pessary. Lancet 1987;ii: 1415-8. public health." Voluntary abortion was legalised in France in 1975 and was now "a right for women ... withdrawing the pill would deprive women of an important scientific advance that makes abortions less painful and traumatic by avoiding the need for surgery." 40

Probably more than one third of the 140 million women in the developing world who became pregnant in 1988 did not want to have another child. ${ }^{41}$ Extrapolating from available data, one third to two thirds of the 25 to 40 million abortions in developing countries are illegal procedures or take place outside the health system and have a high mortality and morbidity. ${ }^{41}$ Clearly there is a great unmet need for contraception, but also, in the real world, there is a need for the mifepristone and prostaglandin combination with all necessary legal safeguards - plus counselling and medical back up for failure of the method or heavy bleeding.

Britain is expected to be the next country after France in which mifepristone is marketed. Indeed, the company last month announced that it would seek a marketing licence in the United Kingdom. ${ }^{42}$ Allowing for the inevitable delay in obtaining full approval from the Committee on the Safety of Medicines, marketing is unlikely before the end of 1991. In Britain "the introduction of RU 486 could result in a saving to the NHS of $£ 10-15 \mathrm{~m}$ annually .. . with an anticipated reduction in patient morbidity an added advantage." ${ }^{43}$

The International Planned Parenthood Federation, in a statement at the meeting in Ottawa in November 1989, expressed its deep concern over the lack of progress in making these products available to women. It deplored the delays ${ }^{44}$; so, I am sure, will most readers of the $B M \mathcal{H}$.

JOHN GUILLEBAUD

Medical Director,

Margaret Pyke Centre,

London WIV 5TW

25 Rodger MW, Logan AF, Baird DT. Induction of early abortion with mifepristone (RU 486) and two different doses of prostaglandin pessary (gemeprost). Contraception 1989;39:497-502.

26 Swahn M-L, Gottlieb C, Green K, Bygdeman M. Oral administration of RU 486 and 9-methyline $\mathrm{PGE}_{2}$ for termination of early pregnancy. Contraception 1990;41:461-73.

27 Cameron IT, Baird DT. A controlled released form of 16-16-dimethyl-trans $\Delta_{2} 2 \mathrm{PGE}_{1}$ methyl ester for early abortion. Contraception 1986;33:121-5.

28 Laboratoires Roussel. Mifégyne (mifepristone): brochure d'information scientifique. Paris: Laboratoires Roussel, 1989:1-36.

29 Radestad A, Christensen NJ, Stromberg L. Induced cervical ripening with mifepristone in first trimester abortion: a double blind randomised biochemical study. Contraception 1988;38:301-12.

30 Gupta JK, Johnson N. Effect of mifepristone on dilatation of the pregnant and non-pregnant cervix. Lancet 1990;335:1238-40.

31 Christensen NJ, Bygdeman M, Green K. Comparison of different prostaglandin analogues and laminaria for pre-operative dilatation of the cervix in late first trimester abortion. Contraception 1983;27:51-61.

32 Rodger MW, Baird DT. Pre-treatment with mifepristone RU 486 reduces interval between prostaglandin administration and expulsion in second trimester abortion. Br $\mathcal{Y}$ Obstet Gynaecol 1990;97:41-5.

33 Cabrol D, D'Yvoire MB, Mermet E, Cedard L, Sureau C, Baulieu E-E. Induction of labour with mifepristone after intrauterine fetal death. Lancet 1985 ;ii: 1019

34 Wolf JF, Sinosich M, Anderson TL, Ulmann A, Baulieu E-E, Hodgen GD. Progesterone antagonist (RU 486) for cervical dilatation, labor induction and delivery in monkeys. Effectiveness in combination with oxytocin. Am f Obstet Gynecol 1989;160:45-7.

35 Hill NC, Selinger M, Ferguson F, MacKenzie IZ. The placental transfer of mifepristone (RU 486) during the second trimester and its influence upon maternal and fetal steroid concentrations. Brf Obstet Gynaecol 1990;97:406-11.

36 Paris FX, Henry-Suchet J, Tesquier L, Logsel T, Loffredo V, Pez JP. Le traitment medical des grossesses extra-uterines par le RU 486. Presse Med 1984:13:1219.

37 Bertagna X, Bertagna C, Laudat M-H, Husson JM, Girard F, Luton P. Pituitary-adrenal responses to the antiglucocorticoid action RU 486 in Cushing's syndrome. $f$ Clin Endocrinol Metab to the antigluce
$1986 ; 63: 639-43$.

38 Romieu G, Maudelonde T, Ulmann A, et al. The antiprogestin RU 486 in advanced breast cancer: preliminary clinical trial. Bull Cancer 1987;74:455-61.

39 Blankenstein MA, van't Verlat JW Croughs RJ. Hormone dependency of meningiomas. Lancet $1989 ; 1: 1381$.

40 Dorozynski A. Tempest in a pill box. Br Med f 1988;297:1291-2.

41 Anonymous. The impact of unsafe abortion in the developing world. Outlook 1989;7:2-7.

42 Prentice T. French hope to market abortion pill in Britain. The Times 1990;23 Jul:4.

43 MacKenzie IZ. RU 486 and the implications for the NHS. In: The abortion pill RU 486. London: Birth Control Trust, 1990.

44 Anonymous. Resolution on RU 486. IPPF Medical Bulletin 1989;23:3-4.

\section{Correction}

Who should take vitamin supplements?

An editorial error occurred in the editorial by Professor Stewart Truswell ( 21 July, p 135). Thiamine ranges from 0.5 to $50 \mathrm{mg}$ per tablet and not $5.0 \mathrm{mg}$ as published. 